\title{
Shaw scalpel use for recurrent laryngeal nerve dissection: safety parameter findings from continuous intraoperative neuromonitoring in swine models
}

\author{
Dawon Park ${ }^{1}$, Ji Young You ${ }^{1}$, Hsien Wen Yang ${ }^{1}$, Ralph P. Tufano ${ }^{2}$, Hoon Yub Kim ${ }^{1}$ \\ ${ }^{1}$ Department of Surgery, KUMC Thyroid Center, Korea University Hospital, Korea University College of Medicine, Seoul, South Korea; ${ }^{2}$ Head \\ and Neck Endocrine Surgery Division, Department of Otolaryngology-Head and Neck Surgery, The Johns Hopkins University School of Medicine, \\ Baltimore, MD, USA \\ Contributions: (I) Conception and design: HY Kim, RP Tufano; (II) Administrative support: All authors; (III) Provision of study materials: HY Kim, \\ RP Tufano; (IV) Collection and assembly of data: D Park; (V) Data analysis and interpretation: D Park; (VI) Manuscript writing: All authors; (VII) \\ Final approval of manuscript: All authors. \\ Correspondence to: Hoon Yub Kim, MD, PhD, FACS. Department of Surgery, Korea University College of Medicine, 73, Inchon-ro, Seongbuk-gu, \\ Seoul 02841, South Korea. Email: hoonyubkim@korea.ac.kr.
}

\begin{abstract}
Background: Precise dissection with hemostasis while preserving important structures is critical in thyroid surgeries. In this study, we tested the safety of the Hemostatix Shaw scalpel (HSS) around the recurrent laryngeal nerve (RLN) in porcine models.

Methods: Four piglets were used to obtain continuous intraoperative neuromonitoring data. The HSS was applied at various distances from the RLN, with various temperature settings. Monopolar electrosurgical pencil and Harmonic scalpel were also tested for comparison.

Results: The use of HSS did not show adverse electromyographic (EMG) events when activated at 3- and 5 -mm distances from the RLN. At a 1-mm distance, adverse event was observed at $300{ }^{\circ} \mathrm{C}$ after 2 seconds of activation. At $210^{\circ} \mathrm{C}$, adverse event was observed when the instrument was directly adjacent to the RLN. For comparison, an electrosurgical pencil, set at coagulation mode $(25 \mathrm{~W})$, showed an irreversible adverse EMG event during 5 seconds of activation at $1-\mathrm{mm}$ distance from the RLN. Harmonic ACE+, activation power at level 5, was also applied in one RLN and reversable adverse EMG event was observed at $<0.1-$ mm (contact) distance after 3 seconds of activation.

Conclusions: The safety distance of the HSS was $3 \mathrm{~mm}$ for the $300{ }^{\circ} \mathrm{C}$ setting and $>1 \mathrm{~mm}$ for the $210{ }^{\circ} \mathrm{C}$ setting in the swine models in this study. Surgeons must understand the specific characteristics of various energy devices and apply them appropriately for safe operation.
\end{abstract}

Keywords: Thyroid surgery; temperature; recurrent laryngeal nerve (RLN); intraoperative neuromonitoring; energy-based device (EBD)

Submitted Mar 11, 2020. Accepted for publication Aug 27, 2020.

doi: $10.21037 /$ gs-20-336

View this article at: http://dx.doi.org/10.21037/gs-20-336

\section{Introduction}

In surgery, maintaining hemostasis occupies a significant amount of operating time and is essential to help prevent surgical complications. For example, thyroidectomy was once associated with massive blood loss, with a mortality rate as high as $50 \%$ in the late 10 th century (1). Various hemostatic techniques have evolved in thyroid surgery since Theodor Kocher introduced suture ligation of the major arteries (1). Among these techniques is the use of energybased devices (EBDs), which allowed for new methods of vessel ligation $(2,3)$. However, these instruments call 
for caution when used near the recurrent laryngeal nerve (RLN), as the RLN is quite vulnerable to lateral spread of thermal damage generated by EBDs (4).

The Hemostatix Shaw scalpel (Hemostatix Medical Technologies, LLC, Bartlett, TN, USA) is a thermally activated scalpel that heats the blade to various degrees of set-point temperature (5) ranging from 70 to $300{ }^{\circ} \mathrm{C}$. The heat cauterizes small blood vessels, and the sharp blade of the Shaw scalpel allows surgeons to perform precise dissection while preserving critical structures such as the RLN in thyroid surgeries. Nevertheless, the heated blade can become a potential source of thermal injury to the adjacent nerve during thyroidectomy, and the risk must be evaluated. Therefore, in this study, we aimed to evaluate the safe application of the Hemostatix Shaw scalpel (HSS) around the RLN in experimental porcine models. We present the following article in accordance with the ARRIVE reporting checklist (available at http://dx.doi. org/10.21037/gs-20-336).

\section{Methods}

\section{Ethical approval}

Experiments were performed under a protocol license (No.: KUIACUC KOREA-2018-0153) granted by institutional board of the Korea University Institutional Animal Care and Use Committee (Seoul, Korea), in compliance with Korea University Institutional guidelines for the care and use of animals.

\section{Subjects}

Four Yorkshire-Landrace-Duroc female piglets weighing $30-40 \mathrm{~kg}$ were individually housed for 7 days for acclimation in the housing facility. The housing facility provided the following environmental conditions for the piglets: a temperature of $23{ }^{\circ} \mathrm{C}, 50 \%$ humidity, 200 lux lighting with 12-hour:12-hour light-dark cycle (lights on at 8:00 AM and off at 8:00 PM). Each cage was $880 \mathrm{~mm} \times 1,360 \mathrm{~mm}$ $\times 950 \mathrm{~mm}$ in size, and the animals were given access to sufficient amounts of maintenance food (Cargill Agri Purina Inc., Seongnam, Korea) and water. The four piglets were evaluated for the threshold for imminent thermal RLN injuries induced by the HSS, the Harmonic ACE+ (Ethicon Endo-Surgery, a subsidiary of Johnson \& Johnson, Cincinnati, OH, USA) and an electrosurgical monocautery pencil (Medtronic, Minneapolis, MN, USA).

\section{Anesthesia}

The animals were fasted for 12 hours prior to the experiment. Xylazine ( $1 \mathrm{mg} / \mathrm{kg}$; Rompun, Bayer, Leverkusen, Germany) and zolazepam/tiletamine ( $7 \mathrm{mg} / \mathrm{kg}$; Zoletil, Virbac S.A., Carros, France) were intramuscularly injected as preanesthetic medication. The pigs were then placed on an operating table in the supine position, with their necks slightly extended. Then, a pulse oximeter and an electrocardiographic device were attached for vital sign monitoring. The pigs were intubated with an inner diameter of 6.0 -mm electromyography (EMG) endotracheal tube (Medtronic, Minneapolis, MN, USA) after vecuronium injection $(0.15 \mathrm{mg} / \mathrm{kg})$ for muscle relaxation. The size of the endotracheal tube was decided by visual inspection of the larynx and confirmed by checking the resistance of the tube during the intubation process. Intravenous access was secured through the auricular vein, and the pigs received a continuous intravenous infusion of lactated Ringer's solution at $5 \mathrm{~mL} /(\mathrm{kg}$.hour) throughout the operation. The tidal volume and respiratory rate were set at $8 \mathrm{~mL} / \mathrm{kg}$ and 15 breaths/min, respectively.

\section{Continuous intraoperative neuromonitoring equipment settings}

The NIM 3.0 nerve monitoring system (Medtronic, Minneapolis, MN, USA) was used with automated periodic stimulations (APS, $2.0 \mathrm{~mm}$; Medtronic, Minneapolis, MN, USA) for continuous intraoperative neuromonitoring (CIONM). In order to monitor the surface EMG changes of the vocal cord muscles in action during the experimental thermal injury of the RLN, the APS was applied to the vagus nerve at a frequency, duration, and current of $1 / 6 \mathrm{~s}$, $100 \mu s$, and $1 \mathrm{~mA}$, respectively. A conventional monopolar stimulation probe (4 pulses/s, $100 \mu \mathrm{s}, 1 \mathrm{~mA}$; Medtronic) was used for identification and intermittent stimulation of the RLN. A 50\% decrease in amplitude or 10\% increase in latency was set as adverse EMG changes. Acoustic and optic alarms were set to alert the surgeons during the experiment.

\section{Energy device equipment settings}

The HSS, Harmonic ACE+ and electrosurgical pencil were used to comparatively evaluate the threshold for imminent thermal RLN injuries. We used the Precision 8400 controller model (Hemostatix Medical Technologies, LLC, Bartlett, TN, USA) and two different heating temperature 
settings, 210 and $300{ }^{\circ} \mathrm{C}$, for the HSS. The activation power of Harmonic ACE+ was set at level 5 with the Ethicon Endo-Surgery Generator G11 (Ethicon Endo-Surgery, a subsidiary of Johnson \& Johnson). For the electrosurgical pencil, the ForceFX Generator C (Medtronic, Minneapolis, $\mathrm{MN}$, USA) was used, with the action mode set at monopolar desiccate coagulation mode $(25 \mathrm{~W})$.

\section{Operation and study design}

A midline, vertical cervical incision was made to subsequently expose the pig's trachea, thyroid gland, RLN, and vagus nerve. After visual identification of the RLN and the vagus nerve, the monopolar stimulation probe was used to confirm the function of the nerves. The vagus nerve was dissected free from the surrounding soft tissue, and the APS electrode was placed on the nerve. The baseline amplitude and latency of the evoked response were automatically calibrated by the Medtronic nerve monitoring equipment. The HSS, Harmonic ACE+ and electrosurgical pencil were applied to the adjacent soft tissue around the RLN at a distance of $5 \mathrm{~mm}$ to $<0.1$ (contact) $\mathrm{mm}$ for up to 5 seconds. If no significant adverse EMG event was observed, the distance from the RLN was progressively shortened from $5 \mathrm{~mm}$ to 3,1 , and $<0.1 \mathrm{~mm}$ (contact). The proximal to the distal part of the RLN was used for each step of the experiment. Activation of the energy device was terminated when an adverse EMG event occurred, and the duration of the activation was recorded. In the event of any adverse EMG incidents, any signs of recovery were monitored for 20 minutes.

\section{Statistical analysis}

Data were collected simultaneously during the experiments. Gathered information were exported to an Excel file (Microsoft Corp., Redmond, WA, USA). The results were then stratified according to the experimental setting to identify differences in the outcomes of the various energy devices' influence on the RLN. Data were presented as categorical values and corresponding percentages.

\section{Results}

\section{Hemostatix}

Hemostatix was applied on six RLNs in four pigs. The detailed information, including the distance from the
RLN, duration of activation, amplitude, and loss of signal, is presented in Tables 1 and 2. HSS was activated at 5-, 3-, $1-$, and $<0.1-\mathrm{mm}$ (contact) distances from the RLN for 5 seconds each time, at two different temperature settings, 210 and $300^{\circ} \mathrm{C}$.

In the $300{ }^{\circ} \mathrm{C}$ setting, all EMG signals were well maintained at 5- and 3-mm distances from the RLN for 5 seconds of activation. However, at the 1-mm distance, two trials had adverse EMG events after 2 seconds of activation. The loss of signal did not recover in all the cases.

In the $210^{\circ} \mathrm{C}$ setting, complete loss of signal was only observed when the instrument was directly adjacent to the RLN. At the $1-\mathrm{mm}$ distance after 4 seconds of activation, partial adverse EMG events were observed in two of the three experiments, but the signal showed recovery after a few minutes. Of the three experiments at $<0.1-\mathrm{mm}$ (contact) distance, two cases showed adverse EMG signals after 2 and 3 seconds of activation and did not recover after 20 minutes.

\section{Electrosurgical pencil and Harmonic ACE+}

An electrosurgical pencil was tested in one RLN for comparison with HSS. The device was set at coagulation mode $(25 \mathrm{~W})$ for the test. At 1-mm distance from the RLN, an adverse EMG event was observed during 5 seconds of activation, and the signal did not recover.

Harmonic ACE+ was also applied in one RLN to obtain data for comparison. The activation power of Harmonic ACE+ was set at level 5. An adverse EMG event was observed at $<0.1-\mathrm{mm}$ (contact) distance after 3 seconds of activation, but the signal showed recovery after some interval.

\section{Discussion}

RLN injury can result in hoarseness or predisposition to aspiration, but when damaged bilaterally, the consequences can become much more serious, such as stridor and acute airway obstruction $(6,7)$. Therefore, RLN injury is considered as one of the most serious complications of thyroid surgery. The RLN receives close attention from thyroid surgeons because of its vulnerability to injury. The RLN is intimately associated with the tubercle of Zukerkandl and ligament of Berry, the latter which binds the thyroid to the tracheal rings. During the thyroid surgery, it is necessary to divide ligament of Berry in order to mobilize the thyroid gland medially. The RLN 
Table 1 EMG signal changes during thermal injury induced by Hemostatix Shaw scalpel at two different temperature settings

\begin{tabular}{|c|c|c|c|c|c|c|c|}
\hline Animal & Temperature $\left({ }^{\circ} \mathrm{C}\right)$ & Distance (mm) & Duration (sec) & \multicolumn{2}{|c|}{ Amplitude $(\mu \mathrm{V})$} & $\mathrm{AE}$ & LOS \\
\hline \multicolumn{8}{|l|}{ No. 1} \\
\hline \multirow[t]{3}{*}{ Side: L } & 210 & 5 & 5 & 1,055 & $561[53]$ & - & - \\
\hline & & 3 & 5 & 1,055 & $676[64]$ & - & - \\
\hline & & $<0.1$ (contact) & 3 & 548 & 70 [13] & + & + \\
\hline \multirow[t]{3}{*}{ Side: $\mathrm{R}$} & 300 & 5 & 5 & 2,040 & $1,944[95]$ & - & - \\
\hline & & 3 & 5 & 2,040 & $1,955[96]$ & - & - \\
\hline & & 1 & 2 & 2,040 & 267 [13] & + & + \\
\hline \multirow{3}{*}{ Side: L } & & 3 & 5 & 352 & 210 [60] & - & - \\
\hline & & 1 & 5 & 352 & 215 [61] & - & - \\
\hline & & $<0.1$ (contact) & 4 & 352 & 68 [19] & + & - \\
\hline \multirow[t]{3}{*}{ Side: $\mathrm{R}$} & 300 & 5 & 5 & 553 & $370[67]$ & - & - \\
\hline & & 3 & 5 & 553 & $308[56]$ & - & - \\
\hline & & 1 & 2 & 553 & $61[11]$ & + & + \\
\hline
\end{tabular}

AE, adverse EMG event; EMG, electromyography.

lies closest to the thyroid gland at this location, along with several small accompanying vessels (8). Hence, close dissection and meticulous attempts of hemostasis of the connective tissue in the vicinity of the nerve put the nerve at risk for injury.

Various electrosurgical units have been chosen by surgeons and used to provide hemostasis around the delicate anatomy. Looking at the instrument used in this study as an example, Harmonic Ace+ uses ultrasonic vibrations to create a high-frequency mechanical energy to increase the temperature of the tissue bundle for cauterization and cutting. Another device used in this study, an electrosurgical pencil, delivers a high-frequency electrical current through an electrode to create a heating effect from tissue resistance; the heat results in tissue destruction. However, the devices do not have direct control of the temperature generated by the instruments. Therefore, the possibility of lateral thermal spread from the devices causing injuries to the surrounding tissues, including the RLN, has been a major issue and investigated in numerous studies (5,9-12). Thermal injuries are vexing because they are difficult to identify visually (9) but can cause permanent functional damage to the nerve by denaturing the endoneurium (13).

The device used in this experiment, the HSS, is shaped like the traditional steel scalpel with applied micro-electric circuitry (a pulsed-DC current) that heats the blade to various degrees of set-point temperature (5) ranging from 70 to $300^{\circ} \mathrm{C}$. As the heated blade directly touches the tissue, heat from the scalpel blade is transferred in incise tissue thereby thermally coagulates and seals blood vessels as it makes surgically sharp cuts. Because the temperature of the scalpel blade can be directly controlled to the desired set point, a surgeon can expect the hemostasis effect through more precise thermal dissection while acutely manipulating the surgical field with a sharp blade tip. Therefore, the main purpose of our study was to investigate the safety parameters of the HSS around the RLN. In particular, we aimed to determine whether any lateral thermal spread from the device would occur when the temperature was set high. While the typical operating temperature of the scalpel is reported to be $120-150^{\circ} \mathrm{C}$ for dermis and $180-220^{\circ} \mathrm{C}$ for other soft tissue (5), we set the test temperature at 210 
Table 2 Comparison of EMG signal changes during thermal injury induced by Hemostatix Shaw scalpel and by the electrosurgical pencil (Animal 3) and Harmonic ACE+ (Animal 4)

\begin{tabular}{|c|c|c|c|c|c|c|c|}
\hline Animal & Device & Distance $(\mathrm{mm})$ & Duration (sec) & \multicolumn{2}{|c|}{ Amplitude $(\mu \mathrm{V})$} & $\mathrm{AE}$ & LOS \\
\hline \multicolumn{8}{|l|}{ No. 3} \\
\hline \multirow[t]{2}{*}{ Side: $\mathrm{L}$} & Electrosurgical pencil Coag 25 & 5 & 5 & 1,104 & $1,104[100]$ & - & - \\
\hline & & 3 & 5 & 1,104 & $1,104[100]$ & - & - \\
\hline \multirow[t]{4}{*}{ Side: $\mathrm{R}$} & Hemostatix $300{ }^{\circ} \mathrm{C}$ & 5 & 5 & 930 & $836[90]$ & - & - \\
\hline & & 3 & 5 & 930 & $821[88]$ & - & - \\
\hline & & 1 & 5 & 930 & $720[77]$ & - & - \\
\hline & & $<0.1$ (contact) & 1 & 930 & $273[29]$ & + & + \\
\hline \multirow{3}{*}{ Side: $\mathrm{L}$} & & 3 & 5 & 1,222 & $1,140[93]$ & - & - \\
\hline & & 1 & 5 & 1,222 & $944[77]$ & - & - \\
\hline & & $<0.1$ (contact) & 3 & 1,222 & 148 [12] & + & - \\
\hline \multirow[t]{4}{*}{ Side: $\mathrm{R}$} & Hemostatix $210^{\circ} \mathrm{C}$ & 5 & 5 & 1,212 & $1,212[100]$ & - & - \\
\hline & & 3 & 5 & 1,212 & $1,212[100]$ & - & - \\
\hline & & 1 & 5 & 1,212 & 809 [67] & + & - \\
\hline & & $<0.1$ (contact) & 2 & 1,212 & $210[17]$ & + & + \\
\hline
\end{tabular}

$A E$, adverse EMG event; EMG, electromyography.

and $300{ }^{\circ} \mathrm{C}$ to create extreme thermal conditions. The experiment showed that in the $210{ }^{\circ} \mathrm{C}$ setting, the scalpel was safely used for an extended period of time without any adverse EMG events up to the 3-mm distance, whereas brief, partial adverse EMG events with recovery were observed at the $1-\mathrm{mm}$ distance. The permanent adverse EMG events were only observed when the scalpel was at a direct contact distance from the RLN for more than 2 seconds of activation. In the $300^{\circ} \mathrm{C}$ setting, the Shaw scalpel was safely used around the nerve at distances of up to $3 \mathrm{~mm}$ from the RLN, whereas permanent adverse EMG events were observed when the scalpel was used at a $1-\mathrm{mm}$ distance from the nerve for over 2 seconds.

Other studies have demonstrated the RLN safety parameters of various advanced-energy devices. For example, Harmonic ACE+ was shown to have a safety distance of approximately $1 \mathrm{~mm}(9,12)$. Ligasure, another commonly used advanced-energy device in thyroid surgery, has been reported to have a safe distance of approximately
$2 \mathrm{~mm}$ to avoid thermal injury (10). Our brief trials with other EBDs (a monopolar electrosurgical pencil and Harmonic ACE+) also demonstrated similar safety parameter values. Although a direct comparison is impossible, our experiment data showed that the HSS has a similar safe distance profile when used around the RLN, without causing thermal injuries and is the first of its kind to report this for the RLN.

Our study has certain limitations. First, this is a pilot animal study with a small sample size. Hence, further studies with larger sample sizes should be considered to reproduce the results and refine the experiment details. Second, because of species differences, caution must be taken in translating our data. Porcine tissues may have different compositions; therefore, the specifics of the data cannot be totally applicable to human surgery. However, the porcine model has been previously proven as a useful and reliable model to reflect real-time laryngeal EMG changes during RLN injury (13-15). Third, the Hemostatix used in 
this study has not been officially introduced in Korea yet. Therefore, although the mechanism of the device is simple, the possible learning curve may occur when using the newly encountered instrument which could affect the test results. Lastly, this study lacks any long-term outcomes of RLN function after using the Shaw scalpel because we focused on the real-time electrophysiological changes during RLN and observed the recovery only for an acute period. However, CIONM data are proven to be reliable for prediction of eventual vocal cord function (16-18).

\section{Conclusions}

In conclusion, the safety distance of the HSS was $3 \mathrm{~mm}$ for the $300{ }^{\circ} \mathrm{C}$ setting and $>1 \mathrm{~mm}$ for the $210{ }^{\circ} \mathrm{C}$ setting in the swine models in this study. Surgeons must understand the specific characteristics of various energy devices and apply them appropriately for safe operation.

\section{Acknowledgments}

Funding: None.

\section{Footnote}

Reporting Checklist: The authors have completed the ARRIVE reporting checklist. Available at http://dx.doi. org/10.21037/gs-20-336

Data Sharing Statement: Available at http://dx.doi. org/10.21037/gs-20-336

Conflicts of Interest: All authors have completed the ICMJE uniform disclosure form (available at http:// dx.doi.org/10.21037/gs-20-336). RPT serves as an unpaid editorial board member of Gland Surgery from September 2020 to August 2022. RPT reports that he is a consultant for Medtronic and Hemostatix. HYK reports that he is a consultant for Medtronic. The other authors have no conflicts of interest to declare.

Ethical Statement: The authors are accountable for all aspects of the work in ensuring that questions related to the accuracy or integrity of any part of the work are appropriately investigated and resolved. In addition, experiments were performed under a protocol license (No.: KUIACUC KOREA-2018-0153) granted by institutional board of the Korea University Institutional Animal Care and Use Committee (Seoul, Korea), in compliance with Korea University Institutional guidelines for the care and use of animals.

Open Access Statement: This is an Open Access article distributed in accordance with the Creative Commons Attribution-NonCommercial-NoDerivs 4.0 International License (CC BY-NC-ND 4.0), which permits the noncommercial replication and distribution of the article with the strict proviso that no changes or edits are made and the original work is properly cited (including links to both the formal publication through the relevant DOI and the license). See: https://creativecommons.org/licenses/by-nc-nd/4.0/.

\section{References}

1. Udelsman $\mathrm{R}$, Chen $\mathrm{H}$. The current management of thyroid cancer. Adv Surg 1999;33:1-27.

2. Dilek ON, Yilmaz S, Degirmenci B, et al. The use of a vessel sealing system in thyroid surgery. Acta Chirurgica Belgica 2005;105:369-72.

3. Shen WT, Baumbusch MA, Kebebew E, et al. Use of the electrothermal vessel sealing system versus standard vessel ligation in thyroidectomy. Asian J Surg 2005;28:86-9.

4. Dionigi G. Energy based devices and recurrent laryngeal nerve injury: the need for safer instruments. Langenbecks Arch Surg 2009;394:579-80.

5. Fee WE Jr. Use of the Shaw scalpel in head and neck surgery. Otolaryngol Head Neck Surg 1981;89:515-9.

6. Serpell JW, Lee JC, Yeung MJ, et al. Differential recurrent laryngeal nerve palsy rates after thyroidectomy. Surgery 2014;156:1157-66.

7. Chandrasekhar SS, Randolph GW, Seidman MD, et al. Clinical practice guideline: improving voice outcomes after thyroid surgery. Otolaryngol Head Neck Surg 2013;148:S1-37.

8. Townsend CM Jr, Beauchamp RD, Evers BM, et al. Sabiston textbook of surgery: the biological basis of modern surgical practice -19 th ed. Philadelphia: Elsevier, 2012:886-923.

9. Wu CW, Chai YJ, Dionigi G, et al. Recurrent laryngeal nerve safety parameters of the harmonic focus during thyroid surgery: porcine model using continuous monitoring. Laryngoscope 2015;125:2838-45.

10. Dionigi G, Chiang FY, Kim HY, et al. Safety of LigaSure in recurrent laryngeal nerve dissection-porcine model using continuous monitoring. Laryngoscope 2017;127:1724-9. 
11. Kwak HY, Dionigi G, Kim D, et al. Thermal injury of the recurrent laryngeal nerve by THUNDERBEAT during thyroid surgery: findings from continuous intraoperative neuromonitoring in a porcine model. J Surg Res 2016;200:177-82.

12. Kim HK, Chai YJ, Lee HY, et al. Comparing the safety of harmonic ACE and ACE+ around the recurrent laryngeal nerve in swine models. Ann Surg Treat Res 2018;94:285-90.

13. Wu CW, Dionigi G, Sun H, et al. Intraoperative neuromonitoring for the early detection and prevention of RLN traction injury in thyroid surgery: a porcine model. Surgery 2014;155:329-39.

14. Wu CW, Lu IC, Randolph GW, et al. Investigation of optimal intensity and safety of electrical nerve stimulation during intraoperative neuromonitoring of the recurrent laryngeal nerve: a prospective porcine model. Head Neck

Cite this article as: Park D, You JY, Yang HW, Tufano RP, Kim HY. Shaw scalpel use for recurrent laryngeal nerve dissection: safety parameter findings from continuous intraoperative neuromonitoring in swine models. Gland Surg 2020;9(5):1363-1369. doi: 10.21037/gs-20-336
2010;32:1295-301.

15. Lin YC, Dionigi G, Randolph GW, et al. Electrophysiologic monitoring correlates of recurrent laryngeal nerve heat. Laryngoscope 2015;125:E283-90.

16. Phelan E, Schneider R, Lorenz K, et al. Continuous vagal IONM prevents recurrent laryngeal nerve paralysis by revealing initial EMG changes of impending neuropraxic injury: a prospective, multicenter study. Laryngoscope 2014;124:1498-505.

17. Schneider R, Randolph GW, Sekulla C, et al. Continuous intraoperative vagus nerve stimulation for identification of imminent recurrent laryngeal nerve injury. Head Neck 2013;35:1591-8.

18. Dionigi G, Donatini G, Boni L, et al. Continuous monitoring of the recurrent laryngeal nerve in thyroid surgery: a critical appraisal. Int J Surg 2013;11 suppl 1:S44-6. 